This information is current as of April 26, 2023.

Sentinel Angiographic Signs of Cerebral Hyperperfusion after Angioplasty and Stenting of Intracranial Atherosclerotic Stenosis: A Technical Note

M. Ghuman, A.C.O. Tsang, J.M. Klostranec and T. Krings

AJNR Am J Neuroradiol 2019, 40 (9) 1523-1525

doi: https://doi.org/10.3174/ajnr.A6149

http://www.ajnr.org/content/40/9/1523 


\title{
Sentinel Angiographic Signs of Cerebral Hyperperfusion after Angioplasty and Stenting of Intracranial Atherosclerotic Stenosis: A Technical Note
}

\author{
(D) M. Ghuman, (D)A.C.O. Tsang, (D).M. Klostranec, and (D)T. Krings
}

\begin{abstract}
SUMMARY: Cerebral hyperperfusion syndrome is a serious complication of endovascular angioplasty and stent placement for longstanding intracranial stenosis, resulting in neurologic dysfunction, seizure, or reperfusion hemorrhage. Rigorous control of blood pressure is commonly used in the perioperative period to prevent cerebral hyperperfusion syndrome, but the optimal blood pressure is often arbitrary. We describe the angiographic features that reflect impaired cerebral autoregulation and microvascular transit abnormality, which may be used to gauge the optimal blood pressure parameters in the immediate postintervention period for prevention of cerebral hyperperfusion syndrome.
\end{abstract}

ABBREVIATIONS: $\mathrm{BP}=$ blood pressure; $\mathrm{CHS}=$ cerebral hyperperfusion syndrome; $\mathrm{ICAS}=$ intracranial atherosclerosis; $\mathrm{ICH}=$ intracranial hemorrhage

C erebral hyperperfusion syndrome (CHS) is a well-described complication associated with cerebral revascularization after extracranial angioplasty and stent placement. ${ }^{1} \mathrm{CHS}$ following intracranial angioplasty is less well-studied but is estimated in observational studies to occur in $3.4 \%$ of patients with nearly $80 \%$ mortality when complicated by intracerebral hemorrhage (ICH). ${ }^{2-4}$ This likely contributed to the adverse outcomes in the intervention arm of the Stenting vs Aggressive Medical Management for Preventing Recurrent Stroke in Intracranial Stenosis (SAMMPRIS) trial. $^{4-6}$

While the exact pathophysiology of CHS is still not fully understood, impaired cerebral autoregulation and cerebral hemodynamic alterations following revascularization are considered the major mechanisms involved. ${ }^{4,5}$ In patients with intracranial atherosclerosis (ICAS), CHS development is associated with poor control of postoperative blood pressure (BP) and impaired collateral circulation. ${ }^{4}$ For extracranial stenosis, other well-known risk

Received April 26, 2019; accepted after revision June 25.

From the Department of Medical Imaging (M.G.), Sunnybrook Health Sciences Centre, Toronto, Ontario, Canada; Division of Neurosurgery (A.C.O.T.), Department of Surgery, The University of Hong Kong, Hong Kong; and Department of Medical Imaging (A.C.O.T., J.M.K., T.K.), Toronto Western Hospital, Toronto, Ontario, Canada.

Mandeep Ghuman and Anderson Chun On Tsang made equal contributions to the article.

Please address correspondence to Anderson Chun On Tsang, MD, Room 701, Administrative Block, Department of Neurosurgery, Queen Mary Hospital, 102 Pokfulam Rd, Hong Kong; e-mail: acotsang@hku.hk

三Indicates article with supplemental on-line table.

Indicates article with supplemental on-line photo.

http://dx.doi.org/10.3174/ajnr.A6149 factors include baseline hypertension, carotid stenosis of $\geq 90 \%$, and impaired cerebrovascular reserve. ${ }^{4-6}$ These factors coupled with maximal arteriolar dilation, compromised cerebral autoregulation, and systemic hypertension translate to an increased cerebral perfusion pressure and cerebral hyperperfusion.

Stringent systemic BP control is a widely used prophylactic strategy in the postrevascularization period and has been shown to reduce the incidence of CHS in high-risk individuals. ${ }^{7,8}$ Ideally, quantitative cerebral blood flow should be monitored to guide the hemodynamic management, but continuous and reliable means of measurement are lacking in routine clinical practice. ${ }^{4,5,8}$ This article illustrates the angiographic signs of hyperperfusion immediately after intracranial stent placement and angioplasty, and their utility in titrating individual BP targets in the postoperative period for the prevention of CHS. This method has been used in our center to select patients for aggressive BP control following intervention.

\section{Techniques}

We treat patients with symptomatic ICAS when they are refractory to aggressive medical treatment or if the ischemic symptom is secondary to critical hypoperfusion downstream of the ICAS stenosis instead of perforator occlusion or artery-to-artery embolism. Typically, predilation of the stenotic intracranial ICA or MCA segment is followed by delivery of a Wingspan stent system (Stryker, Kalamazoo, Michigan). ${ }^{9}$

Immediately after stent placement, a control angiogram is obtained at the baseline systemic BP. Particular attention is paid to the downstream vascular field for 2 sentinel signs suggestive of maximal arteriolar dilation and disrupted cerebral autoregulation 


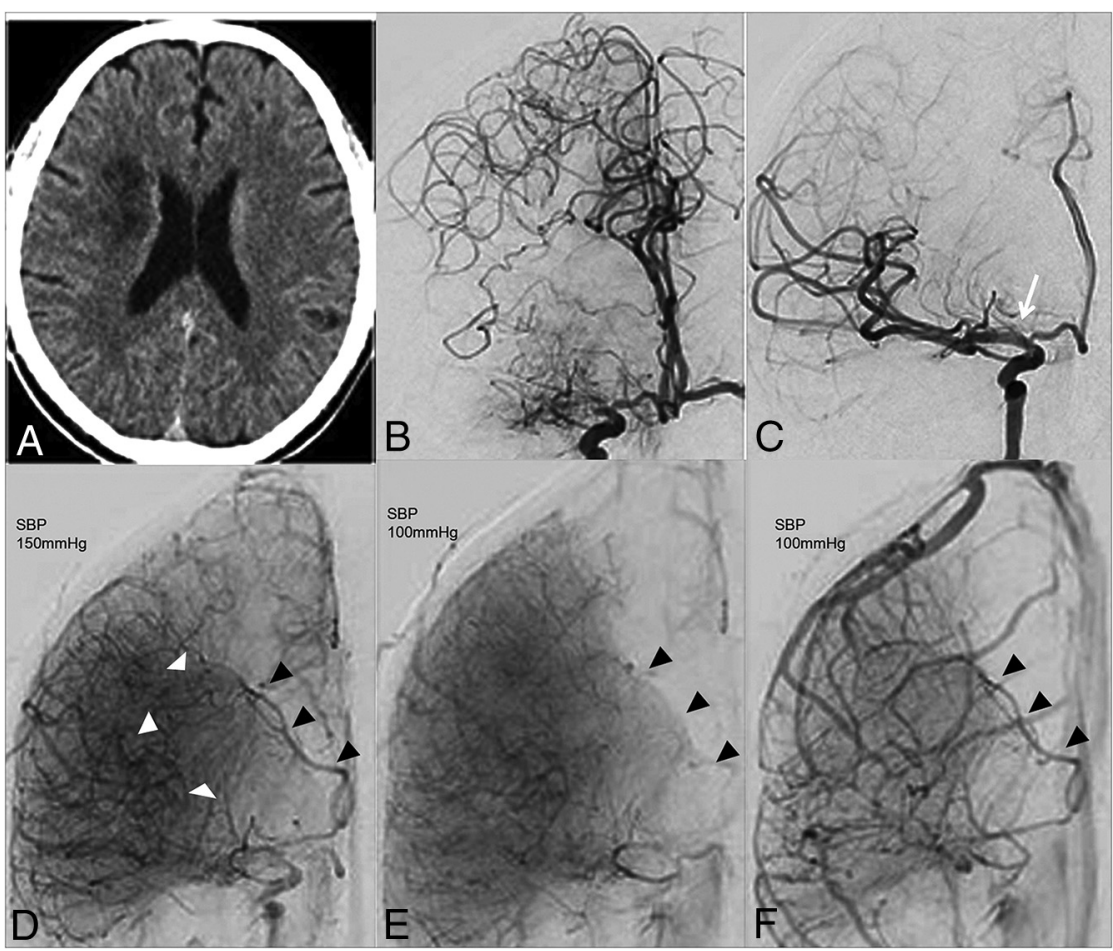

FIGURE. A 66-year-old female patient (patient 1) who presented with left-sided transient ischemic symptoms. A, Noncontrast CT of the brain shows hypodensity consistent with previous ischemic infarct in the right corona radiata in the cerebral internal watershed zone. $\mathrm{CT}$ angiography and CT perfusion (not shown) revealed high-grade stenosis of right mid-M1 segment of the MCA with corresponding large areas of perfusion mismatch suggestive of salvageable ischemia, $B$ and $C$, Pre- and postangioplasty right ICA angiograms demonstrate restoration of the severely compromised lumen of the proximal M1 MCA (white arrow), following angioplasty and stent placement. Note the medial shift of the watershed zone after revascularization, $D$, Late arterial phase angiographic image immediately postangioplasty and stent placement at a baseline systolic blood pressure of $158 \mathrm{~mm} \mathrm{Hg}$ demonstrates early opacification of a vein that drains into the deep venous system (black arrows) with prominent capillary blush in the central MCA territory (white arrowheads). E and F, Capillary and venous phase images obtained at a systolic blood pressure of $100 \mathrm{~mm} \mathrm{Hg}$ depict resolution of early arteriovenous shunting and restoration of homogeneity of the capillary stain, with the filling of the index vein in the normal venous phase. SBP indicates systolic blood pressure.

and thus a risk for hyperperfusion: first, an early draining vein of the treated ischemic territory, defined as early contrast filling of a regular anatomic vein in the late arterial or capillary phase of the angiogram that drains the territory downstream of the treated vessel; second, a prominent capillary blush in the ischemic territory, secondary to abnormal luxurious perfusion of the treated territory in the arterial phase, which becomes denser in the capillary phase compared with the rest of the arterial territory and persists late into the venous phase (Figure and On-line Figure).

In patients with an early draining vein and capillary blush after revascularization, systemic hypotensive therapy is commenced in close collaboration with the neuroanesthesiologist. Control angiograms with the same contrast flow rate (pump injections) are repeated in 10-minute intervals at decreasing $\mathrm{BP}$ thresholds (20 $\mathrm{mm} \mathrm{Hg}$ intervals below baseline) until disappearance of the sentinel signs of hyperperfusion are observed. This BP threshold is then maintained in the first 24 hours postintervention in the neurocritical care unit with the patient being kept intubated and sedated to prevent BP spikes and to better control BP during a 24-hour period. Contralateral angiograms are also obtained to assess the adequacy of perfusion and collateral status, given the potential for ischemia due to the induced hypotensive state. After 24 hours, patients who exhibit the above sentinel signs of hyperperfusion are awakened and BP control is gradually relaxed while closely monitoring symptoms of CHS such as new or worsening headache and/or change in neurologic function. Patients developing these symptoms would receive a prolonged duration of hypotensive therapy.

Of 14 symptomatic patients with ICAS stenosis treated endovascularly from January 2016 to March 2019, four patients had an early draining vein and/or the capillary blush sign immediately after angioplasty at baseline $\mathrm{BP}$ (On-line Table). Individual BP thresholds were titrated using the above-mentioned technique, and continuous hypotensive therapy was maintained with intravenous labetalol infusion for 1-2 days. None of these patients had developed symptoms or complications of CHS at the last clinical follow up, and there were no procedure-related complications. None of the 10 patients in whom no sentinel signs of hyperperfusion were observed developed signs or symptoms of CHS.

\section{DISCUSSION}

The present study describes sentinel angiographic signs of cerebral hyperperfusion following revascularization of patients with ICAS stenosis and how these markers are used in our practice in the immediate postangioplasty phase to identify a BP threshold to avoid CHS and its related complications.

We surmise that the occurrence of an early draining vein and capillary blush in the previously ischemic territory is due to the presence of maximally dilated arterioles and capillary bed secondary to long-standing cerebral ischemia. The localized reduction in vascular resistance and hence shortened arterial-venous transit time resulted in an abnormal early draining vein.

At present, there is no description of angiographic features in the literature for assessing the risk for CHS after ICAS revascularization therapy. Our preliminary and observational results suggest that these angiographic signs can serve as sentinel markers of CHS and can be used to optimize the hypotensive therapy BP threshold individually. Moreover, the average time for CHS complication development following extracranial carotid artery angioplasty and stent placement is 12 hours. ${ }^{5}$ Hence, we institute hypotensive therapy for 24 hours after revascularization in patients at risk of CHS. Intraprocedural and postprocedural transcranial Doppler sonography is another technique to monitor for 
CHS after extracranial carotid endarterectomy and may be of use in the titration of hypotensive therapy. ${ }^{10}$

Angiographic blush and early filling vein were previously described in the setting of acute ischemic stroke following intraarterial thrombolysis or endovascular thrombectomy and were associated with hemorrhagic transformation. ${ }^{11-13}$ In acute ischemic infarct, these signs were thought to be due to hyperemia seen in the early stages of infarction, a so-called "luxury perfusion" state. ${ }^{1-14}$ It is most conceivable that the early venous filling is secondary to rapid cerebrovascular transit and not true shunting. It is believed that blood flow is accelerated secondary to the marked vasodilation as a result of ischemia. ${ }^{12}$ Increased local circulatory rates to maintain perfusion and the opening of precapillary arteriovenous shunts have also been proposed after the initial focal vasodilation effect following infarction. ${ }^{11}$

Although our patients did not have acute infarction, the distal vessels did not immediately recover to their normal state of reactivity after revascularization but rather continued to be maximally dilated. This resulted in the described imaging findings that we believe may be related to an increased rate of postreperfusion hemorrhage. Future work would be needed to validate this approach in a larger patient cohort and to correlate with long-term clinical outcome.

\section{CONCLUSIONS}

In this small study, the angiographic signs of an early draining vein and capillary blush in patients with ICAS stenosis treated with endovascular revascularization were used as sentinel signs to detect cerebral hyperperfusion reflecting the underlying impaired cerebral vascular autoregulation. Progressive reduction of systemic arterial pressure to achieve reversal of these angiographic signs seems to be of clinical use to gauge postangioplasty hypotensive therapy for the prevention of catastrophic complications associated with cerebral hyperperfusion syndrome.

\section{REFERENCES}

1. Abou-Chebl A, Yadav JS, Reginelli JP, et al. Intracranial hemorrhage and hyperperfusion syndrome following carotid artery stenting: risk factors, prevention, and treatment. J Am Coll Cardiol 2004;43: 1596-601 CrossRef Medline
2. Meyers PM, Phatouros CC, Higashida RT. Hyperperfusion syndrome after intracranial angioplasty and stent placement. Stroke 2006;37:2210-11 CrossRef Medline

3. Medel R, Crowley RW, Dumont AS. Hyperperfusion syndrome following endovascular cerebral revascularization. Neurosurg Focus 2009;26:E4 CrossRef Medline

4. Xu S, Wu P, Shi H, et al. Hyperperfusion syndrome after stenting for intracranial artery stenosis. Cell Biochem Biophys 2015;71:1537-42 CrossRef Medline

5. Huibers AE, Westerink J, de Vries EE, et al. Editor's choice: cerebral hyperperfusion syndrome after carotid artery stenting — a systematic review and meta-analysis. Eur J Vasc Endovasc Surg 2018;56: 322-33 CrossRef Medline

6. Chimowitz MI, Lynn MJ, Derdeyn CP, et al; SAMMPRIS Trial Investigators. Stenting versus aggressive medical therapy for intracranial arterial stenosis. N Engl J Med 2011;365:993-1003 CrossRef Medline

7. Abou-Chebl A, Reginelli J, Bajzer CT, et al. Intensive treatment of hypertension decreases the risk of hyperperfusion and intracerebral hemorrhage following carotid artery stenting. Catheter Cardiovasc Interv 2007;69:690-96 CrossRef Medline

8. Kim KH, Lee CH, Son YJ, et al. Post-carotid endarterectomy cerebral hyperperfusion syndrome: is it preventable by strict blood pressure control? J Korean Neurosurg Soc 2013;54:159-63 CrossRef Medline

9. Luo J, Wang T, Peng G, et al. Endovascular treatment of intracranial atherosclerosis stenosis: current debates and future prospects. Front Neurol 2018;9:666 CrossRef Medline

10. Ogasawara $\mathrm{K}$, Inoue $\mathrm{T}$, Kobayashi $\mathrm{M}$, et al. Cerebral hyperperfusion following carotid endarterectomy: diagnostic utility of intraoperative transcranial Doppler ultrasonography compared with singlephoton emission computed tomography study. AJNR Am J Neuroradiol 2005;26:252-57 Medline

11. Salehi Omran S, Boddu SR, Gusdon AM, et al. Angiographic blush after mechanical thrombectomy is associated with hemorrhagic transformation of ischemic stroke. J Stroke Cerebrovasc Dis 2018;27: 3124-30 CrossRef Medline

12. Ohta H, Nakano S, Yokogami K, et al. Appearance of early venous filling during intra-arterial reperfusion therapy for acute middle cerebral artery occlusion: a predictive sign for hemorrhagic complications. Stroke 2004;35:893-98 CrossRef Medline

13. Fritzsch D, Reiss-Zimmermann M, Lobsien D, et al. Arteriovenous shunts and capillary blush as an early sign of basal ganglia infarction after successful mechanical intra-arterial thrombectomy in ischaemic stroke. Eur Radiol 2015;25:3060 - 65 CrossRef Medline

14. Taveras JM, Gilson JM, Davis DO, et al. Angiography in cerebral infarction. Radiology 1969;93:549-58 CrossRef Medline 